\title{
Locations of L2/Ln Sign Language Pedagogy
}

\author{
Jodie M. Ackerman ${ }^{1,2}{ }^{*}$, Ju-Lee A. Wolsey ${ }^{3}$, M. Diane Clark ${ }^{1}$ \\ ${ }^{1}$ Department of Deaf Studies and Deaf Education, Lamar University, Beaumont, TX, USA \\ ${ }^{2}$ Department of American Sign Language and Interpreting Education, National Technical Institute for the Deaf, Henrietta, NY, USA \\ ${ }^{3}$ Department of Audiology, Speech-Language Pathology, and Deaf Studies, Towson University, Towson, MD, USA \\ Email: ‘jackerman@lamar.edu,jwolsey@towson.edu,diane.clark@lamar.edu
}

How to cite this paper: Ackerman, J. M., Wolsey, J.-L. A., \& Clark, M. D. (2018). Locations of L2/Ln Sign Language Pedagogy Creative Education, 9, 2037-2058. https://doi.org/10.4236/ce.2018.913148

Received: September 20, 2018

Accepted: October 23, 2018

Published: October 26, 2018

Copyright $\odot 2018$ by authors and Scientific Research Publishing Inc. This work is licensed under the Creative Commons Attribution International License (CC BY 4.0).

http://creativecommons.org/licenses/by/4.0/

Open Access

\begin{abstract}
There has been tremendous growth in the teaching of sign language as a foreign sign language in elementary/secondary schools, colleges/universities, private businesses, and agencies. While this surge has allowed students to obtain foreign language credit for personal or professional reasons, the acceptance of teaching sign languages has had its challenges. Traditionally, sign language courses have been provided face-to-face using a variety of curricula in diverse departments, academic programs, and degree programs in different countries. This paper acts as a reference guide that provides locations of where sign languages are formally taught around the world, as well as learning about Deaf culture. Historical and current pedagogical practices are also discussed. Looking ahead to the future, one growing trend is providing sign language courses online in a distance-learning format to meet the high demands of interested students and reach a wider population. Moreover, examining the importance of utilizing well-trained and certified instructors, and implementing current pedagogical practices and materials that include appropriate cultural opportunities are needed to effectively teach sign language classes.
\end{abstract}

\section{Keywords}

Sign Language, Foreign Language, Courses, Curricula, Online

\section{Introduction}

The teaching of sign language, as a foreign language or second language (L2), has seen tremendous growth in the last few decades (Quinto-Pozos, 2011; Rosen, 2008; Rosen, 2010). Sign language classes have been taught at various educational institutions; elementary/secondary schools, colleges/universities, private businesses, and agencies. Individuals take sign language classes for personal, professional, and academic interest. Due to a significant number of agencies that pro- 
vide sign language classes for all ages, this paper provides a reference guide to specifically provide locations of elementary/secondary schools and colleges/universities where sign languages are formally taught around the world.

According to the World Federation of the Deaf (WFD, 2016a), there are 70 million Deaf individuals around the world who use over 300 different sign languages including dialects and other sign systems (Gallaudet University, n.d.). In the United States and Canada, the visual sign language used by the majority of Deaf ${ }^{1}$ individuals is American Sign Language (ASL). ASL has become one of the fastest growing foreign languages in agencies, elementary/secondary schools, and post-secondary education (Quinto-Pozos, 2011; Rosen, 2008). It is ranked as the third most widely taught non-English language in the United States after Spanish and French (Gallaudet University, n.d.; Goldberg, Looney, \& Lusin, 2015; Harrington, 2016). This fast surge has allowed students to take ASL to fulfill foreign language requirements (Quinto-Pozos, 2011; Rosen, 2008).

While there is a US comprehensive list (e.g., database) regarding where sign languages are taught, there is not a public list for foreign sign languages taught in other countries. Therefore, the information in this paper required individual searches within individual countries and then by type of educational institution. These searches were through Deaf agencies, elementary/secondary schools, and colleges/universities that teach sign language in different countries. The following eleven countries: United States, Canada, Australia, Brazil, Finland, Germany, Italy, The Netherlands, New Zealand, Sweden, and the United Kingdom are discussed in this paper; therefore, it is not a comprehensive view of sign language as an L2 in all countries around the world.

The emergence and acceptance of teaching ASL, as a foreign language, did not occur without challenges (Rosen, 2008). Originally, sign languages were not considered languages due to a long-standing debate on the characteristics of languages (Rosen, 2008). However, Stokoe (1960), a renowned American linguistics pioneer (known as the "Father of ASL"), recognized ASL as a complete language that included all of the linguistic features such as phonology, morphology, semantics, and syntax (Harrington, 2015; Maher, 1996). He observed that sign languages were equivalent to spoken languages with the exception of modality (e.g., visual versus auditory). As a three-dimensional, visual-spatial language, they have unique characteristics (Mayberry, 2006; Valli, Lucas, Mulrooney, \& Villanueva, 2011; Wilcox \& Occhino, 2016). Given this research into sign linguistics, next we will highlight the process of sign language gaining recognition in different countries.

\section{Overview of the Literature Review}

\subsection{Recognition of ASL in the United States}

The driving force that introduced ASL in the United States was the Education

${ }^{1}$ Capital D in Deaf refers to people who see themselves as a cultural and linguistic minority using a visual language regardless of their audiological status (Padden, 1980). 
for All Handicapped Children Act (EAHCA or Public Law 94-142), which mandated that signing Deaf and hard of hearing students be integrated into classes with hearing and nondisabled peers (Rosen, 2008; Wright, 2010). However, this opportunity created communication barriers for these children (Rosen, 2008; Rosen, 2006) mandating that schools provide instruction in their primary language. Therefore, ASL interpreters were placed in mainstreamed settings (Rosen, 2008). In addition, the Rehabilitation Act of 1973 helped fund interpreter training programs to increase the number of interpreters available (Newell, 1994). This presence of school interpreters sparked the acceptance of ASL in the United States (Rosen, 2006), which led these courses to become popular in schools and agencies (Quinto-Pozos, 2011; Rosen, 2008; Rosen, 2010).

\subsection{Recognition of Sign Languages in Other Countries}

On an international level, the push to recognize sign languages came from a global organization, WFD (2016b), which was established in 1951. The WFD promotes human rights and access to sign language around the world to ensure that Deaf people are provided with a bilingual education. They implement sign language rights worldwide through their international collaborative efforts and advocacy work with Deaf leaders and policymakers. As a result, they significantly pushed to improve the status of national sign languages around the world, as not all sign languages are recognized in their home countries. Recently in December 2017, the WFD (2016a) declared a specific day, September 23, as the "International Day of Sign Languages," showing an example of their advocacy work. This day was placed into the International Week of the Deaf.

Beside these efforts, WFD was instrumental in supporting the recognition of sign languages across the world. The Swedish government recognized Swedish Sign Language (or Svensktteckenspråk-STS in their language) in 1981, as one of the country's official languages and it only national sign language (Svartholm, 2010). Claiming that they would not leave their Deaf citizens without access to Swedish as well as their sign language, Sweden led the efforts in early bilingual signed/spoken language efforts (Mahshie, 1995). Interestingly after being established in Rome, WFD moved to Finland in 1987. It is unclear if Sweden's decisions were part of WFD's decision, but in 1995, Finland became the third country in the world to recognize FSL (Meulder, 2017). This recognition was now moving across the world, as Australia recognized Auslan as "a community language" in 1991 (Vicdeaf, 2011: para 10) and Uganda recognized their sign language (Uganda Sign Language-USL) as an official language in 1995. Other countries followed in the 21st century including New Zealand Sign Language (NZSL) in 2006, Brazilian Sign Language (or Libras/Língua Brasileira de SinaisLGB in their language) in 2002 (Ethnologue, 2017), and British Sign Language (BSL) in 2003 (Batterbury, 2012). However, there were several sign languages such as Italian Sign Language (or Lingua dei Segni Italiana-LIS in their language) (Geraci, 2012) and Dutch Sign Language (or Nederlandse Gebarentaal- 
NGT in their language) that are not yet officially recognized (Schermer, 2012). Even in officially bilingual countries, it has been difficult to obtain formal recognition for sign languages. For example, in Canada, spoken English and French are the official languages but ASL and Quebec Sign Language (or Langue des signesquébécoise-LSQ in their language) have not been given this status. There is some movement to recognizing these sign languages by the federal government in Canada, as they recognize the communication barriers experienced by Deaf people and the importance of including them in society (National Post, 2016).

In addition to the push from WFD (2016c), there are other driving forces leading to the desire to take sign language courses. For example, Sweden requires hearing parents of Deaf children to learn Swedish Sign Language (STS) (Mahshie, 1995), as all Deaf children are expected to have literacy skills in Swedish, English, and STS. Thus classes to learn STS are provided in elementary and secondary schools (Svartholm, 2010). Early intervention programs also push for sign language services to support Deaf children's early communication and linguistic needs (National Association of the Deaf, 2018). The Department of Education in the United Kingdom funded a British Sign Language (BSL) signing project, I-Sign (Signature, 2009) to support interactions between Deaf and hearing individuals. Signing programs for families have also been established; for example, Deaf Children Australia ${ }^{2}$. Last but not least, sign languages courses are found in a variety of interpreting and Deaf Studies programs at colleges/universities providing multiple opportunities to take courses all over the world.

\subsection{Locations Where Sign Languages Are Taught}

While there are over 300 different international sign languages used around the world, sign language courses have been established at a number of formal (e.g., elementary/secondary schools and colleges/universities) and informal (e.g., agencies, private businesses) locations. These courses are taught for various reasons to children, youth, and adults.

\section{Levels of Educational Institutions}

In colleges/universities, sign language courses are found in various academic departments such as World Languages, Modern Languages, Linguistics, Languages, Deaf Studies, and Deaf Education. These courses may be part-time or full-time degree programs; they may be continuing education courses or lead to a certificate, a diploma, associate, bachelor, or master's degrees (Registry of Interpreters for the Deaf, 2014). General locations of where sign languages courses or programs are provided in different countries are provided next.

United States. In the United States, there has been a $4000 \%$ increase in the teaching of ASL at colleges/universities between 1987 and 2005 (Rosen, 2010).

${ }^{2}$ Additional information about the organization can be found at https://deafchildrenaustralia.org.au. 
This extraordinary growth at colleges/universities (Rosen, 2010) places ASL as one of the most popular foreign languages in higher education, in the same category as spoken languages that include Spanish, Italian, German, and French (Lane, Hoffmeister, \& Bahan, 1996). A 2005 survey (Rosen, 2008) found that there were 701 public high schools from 31 states that provided ASL classes during the 2004-2005 academic year. This latest statistic compares to 17 high schools in 1987 (Rosen, 2008).

As of March 2017, there were 210 colleges/universities in the United States that taught ASL, as a foreign language (Wilcox, 2017). The highest enrollment numbers were found in colleges/universities such as Utah Valley University in Utah (592), California State University in Sacramento (613), the National Technical Institute for the Deaf (692) in New York, San Antonio College (938) in Texas, the University of Cincinnati (1216) in Ohio, and California State University in Northridge (2710). While there are other colleges/universities with high enrollments, some of them have much lower enrollments. It is important to look at where the college/university is located (e.g., urban versus rural), and the size of the institution to explain the wide range of enrollment numbers. For a comprehensive list of post-secondary institutions found in the US with the total enrollment number in ASL classes, the Modern Language Association (2017) provides an extensive "language enrollment database" (updated as of 2013) ${ }^{3}$.

Canada. In Canada, ASL is the most common sign language used in the majority of provinces. In Quebec, Langue des signesquébécoise (LSQ) and ASL are used. ASL and LSQ courses are taught at various locations across Canada; British Columbia (BC), Alberta, Saskatchewan, Manitoba, Ontario, Quebec, Nova Scotia, Newfoundland, Prince Edward Island, and New Brunswick. At the college/university level, ASL and LSQ courses, sign language programs, or interpreting programs are found in various departments.

A number of elementary/secondary schools provide ASL classes for credit. They include the Northern Secondary School in the Toronto District School Board (Ontario) ${ }^{4}$, Mount Boucherie Secondary School and Kelowna Secondary School in Central Okanagan School District $(\mathrm{BC})^{5}$, Vancouver Public Schools $(\mathrm{BC})^{6}$, and Edmonton Public Schools (Alberta) ${ }^{7}$.

Australia. Auslan courses are taught at primary/secondary schools, and universities across Australia. The Department for Education and Child Develop${ }^{3}$ For additional information, refer to https://apps.mla.org/flsurvey_search. ${ }^{4}$ Additional information about Northern Secondary School can be found at https://www.thestar.com/yourtoronto/education/2014/04/17/at_northern_secondary_bilingual_incl udes_american_sign_language.html.

${ }^{5}$ Additional information about the secondary schools in BC can be found at http://www.sd23.bc.ca/ProgramsServices/StudentSupportServices/programsactivities/SpecialProject sActivities/Pages/default.aspx.

${ }^{6}$ Additional information about the Vancouver Public Schools can be found at http://vansd.org/programs-items/american-sign-language/.

${ }^{7}$ Additional information about the Edmonton Public Schools can be found at http://www.rockyview.ab.ca/programs_services/assets_programs/locallydevelopedcourses/ldc-cours e-outlines/american-sign-language-and-culture-teacher-friendly-outline. 
ment (DECD) has identified 27 schools that offer an Auslan language program in primary schools. A list of schools is provided in the link below that was updated as of November 2017; however, it is not a complete list ${ }^{8}$.

At the university level, there are three universities that provide Auslan courses. One is at La Trobe University ${ }^{9}$ that provides Auslan courses, as electives. Another institution, Macquarie University ${ }^{10}$, provides several master's degrees and a diploma in various types of Auslan-English Interpreting (e.g., translating and interpreting, advanced translating and interpreting studies, conference interpreting, and translating and interpreting studies). The University of Newcastle ${ }^{11}$ also provides Auslan courses that lead to a diploma in Languages.

New Zealand. NZSL courses can be found at several universities that provide NZSL and Deaf Studies programs such as a bachelor's degree at Auckland University of Technology ${ }^{12}$, and both a bachelor's degree and certificate at Victoria University of Wellington ${ }^{13}$.

Brazil. In Brazil, one can take Libras courses at Universidade Federal de Santa Catarina to obtain a bachelor's degree in either teaching or interpreting ${ }^{14}$.

Finland. Individuals who are interested in learning FSL can take courses at one of several universities. University of Jyväskylä ${ }^{15}$ provide bachelor's or master's degree in FSL, but students have two options to study the language. One option is for native signers to study the language in more detail. The other option is for non-native signers or foreign students to study FSL as a foreign language. Another location is at Humak University of Applied Science ${ }^{16}$ where Finnish and foreign students can learn a new sign language and culture. Diaconia University of Applied Sciences ${ }^{17}$ also provides a degree in interpreting and sign language.

Germany. There are several universities that provide German Sign Language (or Deutsche Gebärdensprache-DGS) courses. One is at Hamburg University

\footnotetext{
${ }^{8} \mathrm{~A}$ list of schools that offer Auslan language programs can be found at https://www.decd.sa.gov.au/sites/g/files/net691/f/decd-schools-offering-auslan.pdf.

${ }^{9}$ Additional information about La Trobe University can be found at https://www.latrobe.edu.au/handbook/2016/undergraduate/assc/arts/disciplines/auslan.htm. ${ }^{10}$ Additional information about Macquarie University can be found at https://courses.mq.edu.au/2018/domestic/postgraduate/graduate-diploma-of-auslan-english-interpr eting.

${ }^{11}$ Additional information about Auslan courses at the University of Newcastle can be found at https://www.newcastle.edu.au/degrees/diploma-in-languages/what-you-will-study/auslan.

${ }^{12}$ Additional information about Auckland University of Technology can be found at https://www.aut.ac.nz/study-at-aut/study-areas/language-culture/undergraduate-courses/sign-lang uage.

${ }^{13}$ Additional information about Victoria University of Wellington can be found at https://www.victoria.ac.nz/explore/study-areas/new-zealand-sign-language/overview.

${ }^{14}$ Additional information about a the university in Brazil can be found at http://structure.ufsc.br/2016/05/03/brazilian-sign-language-libras/.

${ }^{15}$ Additional information about the University of Jyväskylä can be found at https://www.jyu.fi/hytk/fi/laitokset/kivi/opiskelu/oppiaineet/viittomakieli/en.

${ }^{16}$ Additional information about Humak University of Applied Science can be found at https://www.humak.fi/en/erasmus/finnish-sign-language/.

${ }^{17}$ Additional information about Diaconia University of Applied Science can be found at https://www.diak.fi/en/admissions/degree-programmes/ba-programmes/bachelor-of-interpreting-si gn-language-and-interpreting/.
} 
(Universität Hamburg ${ }^{18}$ that also houses the Society for Sign Language, and Institute of German Sign Language and Communication of the Deaf ${ }^{19}$. They provide several undergraduate and graduate degree programs in sign language interpreting and sign languages. Humboldt University of Berlin (Humboldt-Universität zu Berlin $)^{20}$ offers a bachelor's degree in Deaf Studies and a master's degree in Sign Language Interpreting. RWTH AACHEN University houses SignGes, which is the Center for Sign Language and Gesture ${ }^{21}$. In addition, one may earn bachelor, masters and doctoral degrees at this university.

Netherlands. In the Netherlands, several universities provide courses in Nederlandse Gebarentaal (NGT) or Dutch Sign Language. One is at the University of Amsterdam ${ }^{22}$ where there is a minor in NGT. Another location, Wageningen University and Research, provides an eight-week beginners course and teaches introduction to Deaf culture ${ }^{23}$.

Italy. Lingua deiSegniItaliana (LIS) can be learned at universities such as Ente Nazionale Sordi ${ }^{24}$ and the University of Venice Ca's Foscari ${ }^{25}$. Siena School also collaborates with several universities in the United States, as part of a study-abroad program to learn LIS $^{26}$.

Sweden. To learn and study STS, one can attend Stockholm University ${ }^{27}$. Students can take courses to either learn the language as a foreign language or learn the linguistics of STS. Stockholm University also provides a $\mathrm{PhD}$ in STS, which focuses on linguistic research.

United Kingdom. A large number of colleges/universities in the United Kingdom provide opportunities for individuals to learn BSL as a foreign language or become sign language interpreters. Several universities provide degrees such as the University of Wolverhampton that provides a bachelor's degree in BSL/English Interpreting ${ }^{28}$. The University of Central Lancashire (UCLan) pro-

\footnotetext{
${ }^{18}$ Additional information about Hamburg University can be found at https://www.idgs.uni-hamburg.de/en/ueber-das-institut/ggkg.html.

${ }^{19}$ Additional information about the Institute of German Sign Language and Communication of the Deaf can be found at https://www.idgs.uni-hamburg.de/en.htm.

${ }^{20}$ Additional information about Humboldt University of Berlin can be found at https://www.hu-berlin.de/en/studies/counselling/course-catalogue/programme-descriptions/deafko $\underline{\mathrm{mbi}}$.

${ }^{21}$ Additional information about the Center for Sign Language and Gesture can be found at http://www.signges.rwth-aachen.de/cms/ hxlc/SignGes/?lidx=1.

${ }^{22}$ Additional information about the University of Amsterdam can be found at http://www.uva.nl/en/programmes/minors/dutch-sign-lang/sign-language-of-the-netherlands.html.

${ }^{23}$ Additional information about Wageningen University and Research can be found at https://www.wur.nl/en/Education-Programmes/Wageningen-into-Languages/Languages/Other-La nguages/Learning-Dutch-Sign-Language.htm.

${ }^{24}$ Additional information about the university in Italy can be found at http://www.ens.it.

${ }^{25}$ Additional information about the University of Venice can be found at http://www.unive.it/data/course/248059.

${ }^{26}$ Additional information about Siena School can be found at http://www.sienaschool.com/Academics/Deaf-Studies/.

${ }^{27}$ Additional information about Stockholm University can be found at https://www.ling.su.se/english/sign-language-section.

${ }^{28}$ Additional information about the University of Wolverhampton can be found at http://courses.wlv.ac.uk/course.asp?code=IG001H31UVD.
} 
vides both a bachelor's degree in BSL and Deaf Studies and a master's degree in BSL/English Interpreting and Translating ${ }^{29}$. Heriot Watt University provides a masters degree in Interpreting, Translating, and Applied Language Studies ${ }^{30}$. For students who are interested in taking BSL courses for personal interest, to advance their skills, or to communicate with Deaf individuals, several universities provide beginners and advanced courses. They include the University of Leicester $^{31}$, the University of Nottingham ${ }^{32}$, New College Durham ${ }^{33}$, York St. John University $^{34}$, the University of Edinburgh ${ }^{35}$, and University College London $(\mathrm{UCL})^{36}$. UCL recognizes BSL as a foreign language for university applicants and allows students to use it to meet modern foreign language requirements (Tes Reporter, 2017). As a result, UCL is the only university in the UK that requires all undergraduate students to take a foreign language; BSL is on the list with other foreign languages.

This section provided hard-to-find information regarding where sign languages are located around the world. These findings showed how diverse and multilingual these countries were with spoken and signed languages. The next section will discuss the history of how sign languages were taught and how to implement new sign language courses or programs.

\section{History of Pedagogical Practices}

The historical aspects of teaching sign languages has not been heavily researched or documented. Despite this limited research regarding the history of sign language pedagogy, the history of foreign language pedagogical practices or teaching in the classroom placed emphasis on students' mastery of grammar (Watzke, 2007). Mastering grammatical structures and forms does not sufficiently transfer those skills to actual use of the language (Schulz, 1996). While there are several approaches used to teach a foreign language such as the lexical approach, structural approach, and eclectic approach, there are two commonly used approaches

\footnotetext{
${ }^{29}$ Additional information about the University of Central Lancashire can be found at http://www.uclan.ac.uk/courses/ba_hons_british_sign_language_and_deaf_studies.php.

${ }^{30}$ Additional information about Heriot Watt University can be found at https://www.hw.ac.uk/study/uk/undergraduate/british-sign-language-interpreting-translating-andapplied-language.htm.

${ }^{31}$ Additional information about the University of Leicester can be found at https://www2.le.ac.uk/departments/modern-languages/lal/LANGUAGEScourses/british-sign-langu age-1.

${ }^{32}$ Additional information about the University of Nottingham can be found at https://www.nottingham.ac.uk/cpdstudy/programmes/arts/languages/british-sign-language/britishsign-language.aspx

${ }^{33}$ Additional information about New College Durham can be found at http://www.newcollegedurham.ac.uk/course/british-sign-language-level-1-4157/.

${ }^{34}$ Additional information about York St. John University can be found at https://www.yorksj.ac.uk/study/professional/british-sign-language/.

${ }^{35}$ Additional information about the University of Edinburgh can be found at https://www.ed.ac.uk/studying/short-courses/subjects/languages-courses/british-sign-language.

${ }^{36}$ Additional information about University College London can be found at http://www.ucl.ac.uk/dcal/study/short-and-online-courses/bsl-linguistics.
} 
to foreign language teaching; grammatical (or grammar-based/formal) and functional notional (or communication-based/informal). These two commonly used approaches are described next.

\subsection{Grammatical Approach}

The grammatical approach places most of the emphasis on grammatical mastery or forms that includes phonological forms, morphological forms, syntactic patterns, and lexical items (Canale \& Swain, 1980). It also divides learning objectives into performance objectives (seeking proof of mastery of each) such as changing a present verb to its past tense. As the fields of sociolinguistics and psycholinguistics emerged beginning in the 1970s, a shift away from the grammatical approach occurred. This shift led to individuals actively learning a foreign language in context that provides an authentic learning experience known as the functional notional approach.

\subsection{Functional Notional Approach}

A British linguist, Wilkins, proposed the functional notional approach (1972; as cited in Canale \& Swain, 1980), which was to connect proficient language models with students, and teach them the meaning within the context of a natural social situations, which was better aligned with new information regarding the nature of foreign language learning (Canale \& Swain, 1980; Guntermann, 2001). The grammatical features of the language were not formally taught explicitly, but learned and corrected in context through natural and interactive conversations based on specific communicative functions such as describing, apologizing, requesting, arguing, and inviting (Berns, 1983; Canale \& Swain, 1980).

For optimal foreign language learning that is similar to natural language acquisition, conversations should be encouraged to occur naturally in which the ability to "produce or understand utterances [is] more important [and] appropriate to the context in which they are made" (Campbell \& Wales, 1970; as cited in Canale \& Swain, 1980: p. 4). As a result, the functional notional approach has been an effective and practical approach when teaching foreign languages (Berns, 1983; Smith, Lentz, \& Mikos, 2008). Because of the success using the functional notional approach, a variety of ASL curricula were developed, and used in a number of high schools and colleges/universities in the United States. Signing Naturally is one ASL curriculum that is widely used by ASL instructors that uses the functional notional approach (Smith et al., 2008).

Learning a foreign sign language in a full language immersion program with cross-cultural interaction should be implemented at all levels of educational institutions for effective language instruction. The goal is to keep students motivated by engaging them in interactive group activities, teaching them about appropriate Deaf cultural behaviors (e.g., eye gaze, turn taking, leave taking), showing them how to respect Deaf culture prior to attending Deaf community events, and developing communicative purposes in order to interact with Deaf 
individuals in the community (Smith et al., 2008). There is greater student participation and communication competence within the functional approach than the structural approach (Ahmed, 2013), leading to more effective skill development. Therefore, the goal of teaching a foreign language through the functional notional approach is to provide students with information, practice, and experience that meet their communicative needs rather than learn the grammar of a language (Canale \& Swain, 1980).

\section{Current Pedagogical Practices}

Current sign language pedagogical practices vary by countries. A number of educational institutions have created, developed, and implemented sign language programs or classes to meet the needs of students in different countries. This first section will discuss program implementation, curricular materials, and teaching strategies.

\subsection{United States}

Historically, the process of implementing sign language programs in high schools in the United States involved numerous parties that varied in different states according to a national survey completed in 2005 (Rosen, 2008). One case originated with teachers who knew ASL and wanted to teach it as a foreign language for credits to students (Rosen, 2008). Another case was by a chairperson of a language department who contacted the state department of education to inquire if sign language can be accepted as a foreign language credit for graduation (Rosen, 2008). The last case involved interpreters who made an inquiry to the principal if students can get foreign language credit for taking sign language classes (Rosen, 2008). Through their initiatives, they all went through a similar process to gain support from schools, teachers, parents, teachers, and the community to implement sign language classes (refer to Rosen, 2008). While it was no easy feat, it was important to look at the needs of schools, resources, and availability. At the college level, the first sign language class was offered on a college campus by DePaul University (Chicago, Illinois) in 1965 (Shroyer \& Holmes, 1980). The National Association for the Deaf (NAD) established the Communication Skills Program in 1973, which encouraged schools and agencies serving Deaf people to offer sign language courses (Newell, 1994). Not only did the US implement various sign language programs, other countries also implemented similar sign language programs.

\subsection{Other Countries}

Research studies were not easily found regarding how sign language programs were implemented around the world. However, a large push was through early intervention where parents needed to learn sign language to communicate with their infants (Snodden, 2014). These curriculum tend not to follow the traditional functional approach as they are community based and do not require high 
levels of academic fluency; rather the goal is age typical parent-infant communication. In Canada, the Mother Goose curriculum ${ }^{37}$ is in book form, which is currently being developed into a curriculum (K. Snodden, personal communication, December 15, 2017). These sign language projects have initiated the need to implement sign language classes for parents and families, which are not yet well developed.

In summary, implementation of sign language programs in schools and agencies varied in the US, Canada, and around the world. The big push to implement such programs at the high school level were either from teachers, chairpersons, and sign language interpreters who wanted to teach ASL as a foreign language credit. In addition, parents in early intervention programs needed a way to communicate with their Deaf children; thus there was a need for sign language classes. Besides implementing sign language programs, the next section discusses what types of curricular materials were used to teach sign language.

\section{Current Pedagogical Practices: Curricular Materials}

Different types of curricular materials for teaching sign languages have been developed around the world. They differ by standards and what is being taught such as vocabulary, grammar, usage in different contexts, and cultural knowledge. The following countries are discussed; United States, Canada, Australia, Germany, Sweden, Italy, and Britain.

\subsection{United States}

Since the beginning of providing sign language courses in the United States, various curriculums have been used. In fact, the majority of curricula are old and dated, and developed to be taught face-to-face. The Signing Naturally curriculum is one common curriculum that is still used by the majority of instructors (Smith et al., 2008). This curriculum was developed for students to learn natural conversational skills in a social context, which occur in real life situations, as well as Deaf cultural knowledge (Smith, 1988). Other ASL curricula include: 1) A Basic Course in American Sign Language; 2) ASL at Work; 3) American Sign Language: The Easy Way; 4) Bravo ASL! Curriculum, Student Workbook, Videocourse; and 5) The American Sign Language Phrase Book (refer to Rosen, 2010 for detailed information).

\subsection{Canada}

In Canada, several ASL curricula have been developed in different provinces for both Deaf and hearing students. For non-signing students who take ASL or LSQ courses, the Signing Naturally curriculum has been used (Canadian Hearing Society, 2018). In Manitoba, an ASL curriculum was developed in 2015 for high school students entitled, "American Sign Language and Deaf Culture (ASL \&

${ }^{37}$ Additional information about the Mother Goose curriculum can be found at http://www.mothergoosetime.com/. 
DC): Manitoba Curriculum Framework of Outcomes" (Manitoba Education, 2017). These students study ASL as an L2 and learn about the rich cultural heritage of the Deaf community. General learning outcomes are established to ensure that students gain language competence, knowledge, and appropriate attitudes to use ASL effectively with Deaf individuals.

A joint international project between the Netherlands and Carleton University developed a formal sign language curriculum for parents in 2012-2015 ${ }^{38}$. This project supported parents to become proficient in sign language and effectively communicate with their Deaf child rather than learn informally during home visits. Parents tracked their own learning, and met sign language learning needs and goals by completing seven modules. This formal sign language curriculum was aligned to the Common European Framework of Reference (CEFR) for language (Snodden, 2016).

\subsection{Auslan Curriculum}

Australia developed the first national Auslan curriculum in 2017; referred as the "F-10 Curriculum"39. It included two strands (e.g., communicating and understanding) and four aims to learn Auslan as a first language for Deaf students or as a foreign sign language for hearing students. This groundbreaking curriculum established consistency with standards and provisions for teaching Auslan on a formal level.

\subsection{German Sign Language Curriculum}

The Institute of German Sign Language and Communication of the Deaf at the University of Hamburg use Basic Course German Sign Language Level I \& II Workbook and German Sign Language dialogues in video forms, as well as Signing Naturally for the beginning courses (Universität Hamburg, 2018). For the advanced courses, they use Grammar of German Sign Language from the perspectives of Deaf professionals (Universität Hamburg, 2018). Students are also provided with a variety of German linguistic and seminar texts, film and audio-based exercise materials to practice their receptive and productive skills, as well as their voicing, translation, and interpreting skills (Universität Hamburg, 2018).

\subsection{Swedish Sign Language Curriculum}

The Department of Linguistics at Stockholm University (2018a) has a sign language section in which they have conducted a large body of research on STS since 1972. The department offers courses focusing on either the linguistics of STS or STS as a foreign language (Stockholm University, 2018a). STS as an L2

\footnotetext{
${ }^{38}$ Additional information about the formal language curriculum can be found at https://zeroproject.org/practice/canada-carleton-university/.

${ }^{39}$ Additional information about F-10 Curriculum can be found at

https://www.australiancurriculum.edu.au/f-10-curriculum/languages/auslan/.
} 
for Deaf individuals is another section within the department (Stockholm University, 2018b). This section works closely with the research section focusing on Swedish as an L2, which is offered for Deaf and hearing students (Stockholm University, 2018b). Its main focus is how students learn Swedish as an L2 (Stockholm University, 2018b). Courses are also offered to non-students that are based on theories and skills (Stockholm University, 2018b). Moreover, the department offers professional training or professional development courses for teachers who are interested in working with Deaf students (Stockholm University, 2018b). All courses are taught in Swedish and/or STS (Stockholm University, 2018b).

\subsection{Italian Sign Language Curriculum}

Siena School for Liberal Arts is the only school that offers two programs as part of their semester and summer curriculum; Deaf Studies and Sign Language (Siena School for Liberal Arts, 2018a). Their Deaf Studies program offers a unique study-abroad opportunity related to Deaf culture and sign language for any ASL users in which they experience a full linguistic and cultural immersion into the Italian Deaf world (Siena School for Liberal Arts, 2018b). Their curriculum includes LIS, Italian Deaf Culture and History, and Italian language, as well as an intensive research program (Siena School for Liberal Arts, 2018b).

\subsection{British Sign Language Curriculum}

A project through UCLAN established an online curriculum for instructors in higher education to teach BSL, "British Sign Language: Quality Embedding of the Discipline" (BSL:QED) in 2007 (Centre for Languages, Linguistics, \& Area Studies, 2016 $)^{40}$. It adopted the CEFR's benchmarks as there were no others available. BSL:QED was implemented to develop a common framework of academic standards and qualifications to teach BSL (BSL-QED, 2018). With the number of universities in the United Kingdom offering BSL courses, this online curriculum was developed in partnership with UCL, linguists, and stakeholders to ensure common standards, assessments, and teaching methods.

In summary, each country develops and establishes their own standards when implementing sign language programs. Sign language curricula vary by region, state, and program (Rosen, 2010). There is an increased need for more current pedagogical practices to meet the diverse needs of individuals taking sign language classes. In order to make that happen, it is necessary for sign language curricula to be updated, developed, or created that best fits current pedagogical practices. Sign language has evolved over the years; therefore, it does not meet the old sign language curricula. In addition to needing current curricular materials to teach sign language, effective teaching strategies must be implemented for positive learning.

${ }^{40}$ Additional information about the BSL curriculum can be found at http://www.bslqed.com/BSL_Curriculum_Outline-i-7.html. 


\section{Current Pedagogical Practices: Teaching Strategies}

Teaching sign languages requires a visual modality for visual input regardless of the curriculum and teaching strategy used (Quinto-Pozos, 2011). As mentioned earlier, sign language is a three-dimensional, visual-spatial language that has unique linguistic and nonlinguistic features unlike a spoken language (Quinto-Pozos, 2011). Several teaching strategies are discussed next.

\subsection{No-Voice Policy in the Classroom}

One way to effectively teach sign language to students in the early stages of learning is to incorporate a "no-voice" policy in the classroom from the first day of class (Smith et al., 2008). Instructors often establish a rule that students leave their voices at the door prior to entering the classroom, including no talking, whispering, or mouthing of words. Generally, some students think that it is easier to learn sign language by using spoken language at the same time (Smith et al., 2008). However, it is not recommended, as learning and teaching signed languages requires a different input (e.g., visual; Bauman, Nelson, \& Rose, 2006). Not voicing in the classroom is initially a challenge. More importantly, this policy respects the linguistic and cultural beliefs of the Deaf community who use sign language.

\subsection{Deaf versus Hearing Instructors}

There is an ongoing issue in regards to who is the best person to teach sign language. Many believe that hiring a Deaf person reflects best practices (ASLTA, 2017; Quinto-Pozos, 2011). These Deaf individuals are thought to be appropriate candidates because they are the core of the Deaf community and use the language everyday (ASLTA, 2017; Quinto-Pozos, 2011). They can also provide a cultural learning environment that incorporates social-cultural history and cultural knowledge (Quinto-Pozos, 2011). Learning a foreign language is intertwined with learning the culture of those who use the language (Bauman et al., 2006). For instance, individuals who embrace a signed language as their first language, cherish Deaf culture (Padden \& Humphries, 1988). ASLTA (2017) believes that teachers, whether Deaf or hearing, should have the qualifications mentioned above. They need to be able to represent sign language and Deaf culture as thoroughly as possible to provide an authentic, rich cultural experience with an embedded linguistic learning experience (ASLTA, 2017).

\subsection{Deaf Tutors and Sign Language Labs}

In addition to having Deaf instructors, students can strengthen their sign language skills and be immersed in Deaf culture by working with Deaf tutors, attending a sign language lab/language center, and participating in a sign language club. A number of colleges/universities in different countries provide sign language labs/language centers where students practice and review their sign lan- 
guage skills with other students and tutors such as Lamar University ${ }^{41}$, Western Kentucky University ${ }^{42}$, the University of Cincinnati ${ }^{43}$, and Carleton University ${ }^{44}$. These sign language labs provide students with opportunities to learn and use a visual language with other students, staff, faculty, and community members, as well as improve their understanding of the Deaf cultural community.

In summary, with appropriate teaching strategies to teach sign language, it is important to respect the cultural and linguistic beliefs such as enforcing the no-voice policy. By using instructors and tutors who are knowledgeable about sign language and Deaf culture, they can provide a rich, cultural, linguistic experience for students. Learning sign language cannot be acquired without learning the culture of the Deaf community and being in an ASL-friendly environment. To meet the high demands of students and reach a wider population, future trends must take place to effectively teach and provide sign language courses.

\section{Future Pedagogical Applications}

With the growing rise of students taking sign language classes around the world, there is a need to establish effective sign language programs and best pedagogical practices. There are several suggestions to consider for the future teaching and learning of a foreign sign language.

\subsection{Online Format}

Due to the high demand of college/university students in the United States expressing an interest in learning ASL, beginning in 2009 a trend began to provide courses online (Mortensen, 2015). The role of advanced technology has provided multiple methods and benefits to deliver educational content in traditional and non-traditional formats (e.g., hybrid and online). The online format is a popular future trend to teach sign language, as student enrollment grows in sign language programs. In fact, there is tremendous growth in online higher education courses (Craig, 2015). One faculty member, who teaches ASL courses online at Utah State University (USU), developed the "first ASL teaching series online in the United States" in 2009 (Mortensen, 2015: para 29). The use of technology, media, video conferencing, and video chat programs enhance the online learning environment (Mortensen, 2015). While there is no exact count of the number of institutions that provide sign language courses online, a small number of colleges/universities have moved to this format.

With more sign language courses being provided in a distance-learning format, there are benefits and challenges to this non-traditional online learning

\footnotetext{
${ }^{41}$ Additional information about Lamar University can be found at https://www.lamar.edu/fine-arts-communication/deaf-studies-deaf-education/about/facilities.html.

${ }^{42}$ Additional information about Western Kentucky University can be found at https://www.wku.edu/asls/lab/hours/.

${ }^{43}$ Additional information about the University of Cincinnati can be found at http://cech.uc.edu/education/programs/asl/asllab.html.

${ }^{44}$ Additional information about Carleton University can be found at https://carleton.ca/slals/lrr/.
} 
format. One of the primary benefits is that these online courses "make ASL via distance learning possible not only for USU students...but for students in rural and remote areas, at regional campuses where ASL instructors are in short supply" (Utah State University, 2009: para 4). Online sign language courses reach a wider audience of all ages and unite students around the world. To support students' online learning, they virtually attend sign language labs to allow them to interact with other students similarly to students who attend the lab in person (Mortensen, 2015). In addition, this online format caters to the needs of diverse students who cannot take sign language courses in a traditional setting; yet it provides them with flexibility, convenience, self-paced learning, comfort, choice of school/program, and effective time management to learn a foreign language and culture (Murphy, 2014).

On the other hand, learning sign language online has its challenges if one is used to learning face-to-face on campus. Traditionally, sign language has been taught in a classroom due to being a hands-on and visual language (Utah State University, 2009). However, the USU faculty member has found that "the online course gives students an advantage to go back and relearn those things they may not understand as many times as they want to click their mouse" (Utah State University, 2009: para 6). Another challenge is finding adequate resources and keeping the class size small to provide effective individual interactions between instructor and students; however, more instructors are needed to teach sign language courses online to keep up with the growing demand of students expressing interest (Mortensen, 2015).

\subsection{GoReact}

Another suggestion for effective learning and student success with any foreign language learning is the importance of providing interaction and feedback. Historically, instructors were limited to providing their students with written feedback on assignments done in sign language. Now with GoReact, instructors have an online video recording tool that provides time-coded feedback "for a total immersion experience" (GoReact, 2017: para 1). GoReact is a "cloud-based video software for feedback" that was developed at Brigham Young University in 2010 in the US (GoReact, 2012). It is not only a video recording tool that provides feedback for students taking sign language courses, but also for public speaking, presentations, student teaching observation, and different types of performances (GoReact, 2017).

GoReact provides feedback in two ways on video recordings: real time commentary and previously recorded videos (GoReact, 2017). Instructors can set who can see the videos, create or see comments, and set due dates of the video recordings (GoReact, 2017). Their time for providing feedback becomes efficient (Crook et al., 2012). Because of the time-coded feedback, students can find exactly where their mistakes are in their assignments, and can correct or improve their sign language skills (GoReact, 2017). This feedback has a positive impact 
on their learning (Rochester Institute of Technology, n.d.), which helps enhance their sign language skills (Abrahamson, 2010), and to be engaged with feedback (Crook et al., 2012). With these positive features, GoReact is becoming a technological trend for colleges/universities who provide sign language classes.

\subsection{Preparing Sign Language Teachers}

Another growing trend is graduate degrees in sign language education, which are offered at several universities in the United States such as Gallaudet University and the University of Northern Colorado. Before this academic degree existed, individuals taught ASL in various settings without any formal training and certification. The graduate program "prepares future sign language teachers who will provide exemplary leadership in the sign language teaching field" (Gallaudet University, 2017: para 1), as well as competent sign language instruction (University of Northern Colorado, 2017). Students are taught how to teach sign language by learning theoretical and methodological issues that relate to sign language instruction such as curriculum development (including Deaf Culture) and assessment (Gallaudet University, 2017). In addition, they become a "change agent" in the field of sign language education and spread awareness of the importance of highly qualified and certified sign language instructors (Gallaudet University, 2017). These instructors teach in elementary, secondary, and post-secondary schools, both face-to-face and online in distance-learning format (University of Northern Colorado, 2017).

In summary, advanced technology has made a significant impact on current pedagogical practices. The online format and the use of GoReact has become popular in higher education that draws a large population of diverse students who want to learn a foreign language. It has made a positive impact at universities and colleges; however, there are some drawbacks with online courses. One drawback is that some universities and colleges may not have enough resources to support the online format. Since the number of graduate degrees in sign language education has increased dramatically, universities and colleges can take advantage of hiring highly qualified and certified sign language instructors to teach both face-to-face and online courses.

\section{Future Research Studies}

With these findings, future research is needed to investigate and evaluate the effectiveness of foreign sign language programs, curricula, and instructors to ensure that common standards and benchmarks are established. A database needs to be created that provides a listing of locations where sign language classes are offered. More current pedagogical practices and materials need to be implemented that include cultural opportunities due to the number of outdated sign language curriculums that focus on vocabulary and grammar. By improving sign language instruction and utilizing well-trained instructors who are certified, it can meet the growing demands of students who continue to take sign language 
classes in schools. Finally, future research should look into how to effectively teach sign language classes online with advanced technology; therefore new teaching resources and strategies are needed.

\section{Conclusion}

In conclusion, learning a foreign sign language continues to be a popular and growing trend in agencies, elementary/secondary schools and colleges/universities around the world for all learners (Quinto-Pozos, 2011; Rosen, 2008). With over 300 different sign languages used internationally, students have multiple opportunities to learn an L2 and its culture, as well as obtain foreign language credit (Quinto-Pozos, 2011; Rosen, 2008). Traditionally, foreign sign language courses have been taught face-to-face in a classroom setting in which instructors used a variety of sign language curricula that taught students communicative competence in natural conversations (Canale \& Swain, 1980; Guntermann, 2001). However, one growing trend that will increase in the future is providing sign language courses online in distance learning format. Regardless of how sign languages are taught, this chapter provided a general reference of locations where individuals can learn sign language and Deaf culture around the world.

\section{Conflicts of Interest}

The authors declare no conflicts of interest regarding the publication of this paper.

\section{References}

Abrahamson, E. (2010). Assessment through Video-Feedback on an Undergraduate Sports Rehabilitation Programme. Higher Education Academy [HEA] Case Study. http://www.heacademy.ac.uk/assets/hlst/documents/case_studies/147_abrahamson_vid eo-feedback.pdf

Ahmed, A. (2013). The Functional Approach to Second Language Instruction. World Journal of English Language, 3, 92-105.

American Sign Language Teachers Association (2017). About. https://aslta.org/

Batterbury, S. C. E. (2012). Language Justice for Sign Language Peoples: The UN Convention on the Rights of Persons with Disabilities. Language Policy, 11, 253-272. https://doi.org/10.1007/s10993-012-9245-8

Bauman, H. D. L., Nelson, J. L., \& Rose, H. M. (2006). Signing the Body Poetic: Essays on American Sign Language Literature. Berkeley, CA: University of California Press.

Berns, M. S. (1983). Functional Approaches to Language and Language Teaching: Another Look. In S. J. Savignon, \& M. S. Berns (Eds.), Communicative Language Teaching: Where Are We Going? (pp. 4-22). Urbana: Language Learning Laboratory, University of Illinois at Urbana-Champaign.

BSL-QED (2018). European Framework Part I. http://bslqed.com/European_Framework-i-6.html

Canadian Hearing Society (2018). Sign Language Classes for Individuals. http://www.chs.ca/services/sign-language-classes-individuals 
Canale, M., \& Swain, M. (1980). Theoretical Bases of Communicative Approaches to Second Language Teaching and Testing. Applied Linguistics, 1, 1-47.

https://doi.org/10.1093/applin/1.1.1

Centre for Languages, Linguistics, \& Area Studies (2016). British Sign Language: Quality Embedding of the Discipline (BSL:QED). https://www.llas.ac.uk/projects/2841.html

Craig, R. (2015). A Brief History (and Future) of Online Degrees.

https://www.forbes.com/sites/ryancraig/2015/06/23/a-brief-history-and-future-of-onli ne-degrees/\#c9f39bf48d9a

Crook, A., Mauchline, A., Mawc, S., Lawson, C., Drinkwater, R., Lundqvist, K., Park, J., et al. (2012). The Use of Video Technology for Providing Feedback to Students: Can It Enhance the Feedback Experience for Staff and Students? Computers and Education, 58, 386-396. https://doi.org/10.1016/j.compedu.2011.08.025

Ethnologue (2017). Brazilian Sign Language. https://www.ethnologue.com/language/bzs

Gallaudet University (2017). M.A. in Sign Language Education.

http://www.gallaudet.edu/academic-catalog/graduate-education/departments-and-prog rams/department-of-american-sign-language-and-deaf-studies/ma-in-sign-language-e ducation

Gallaudet University Library (n.d.). Sign Languages of the World by Name. http://libguides.gallaudet.edu/content.php?pid=114804\&sid=991940

Geraci, C. (2012). Language Policy and Planning: The Case of Italian Sign Language. Sign Language Studies, 12, 494-518. https://doi.org/10.1353/sls.2012.0006

Goldberg, D., Looney, D., \& Lusin, N. (2015). Enrollments in Languages Other than English in United States Institutions of Higher Education, Fall 2013.

https://www.mla.org/content/download/31180/1452509/EMB_enrllmnts_nonEngl_201 3.\%0Apdf

GoReact (2017). ASL and Interpreter Training. http://get.goreact.com/asl/

GoReact (2012). GoREACT Case Study: Brigham Young University. https://www.youtube.com/watch?v=-7epqP_XHog

Guntermann, G. (2001). Designing Programs for Foreign Languages. Theory into Practice, 26, 276-281. https://doi.org/10.1080/00405848709543286

Harrington, T. (2015). ASL: Academic Acceptance and Official Recognition. Gallaudet University Library.

http://libguides.gallaudet.edu/content.php?pid=114804\&sid=991858

Harrington, T. (2016). Ranking and Number of Users. Gallaudet University Library. http://libguides.gallaudet.edu/content.php?pid=114804\&sid=991835

Lane, H., Hoffmeister, R., \& Bahan, B. (1996). A Journey into the Deaf-World. San Diego, CA: DawnSignPress.

Maher, J. (1996). Seeing Language in Sign: The Work of William C. Stokoe. Washington DC: Gallaudet University Press.

Mahshie, S. N. (1995). Educating Deaf Children Bilingually: With Insights and Applications from Sweden and Denmark. Washington DC: Pre-College Programs, Gallaudet University.

Manitoba Education (2017). International and Heritage Languages. http://www.edu.gov.mb.ca/k12/cur/languages/asl/framework/index.html

Mayberry, R. I. (2006). Learning Sign Language as a Second Language. In K. Brown (Ed.), Encyclopedia of Language and Linguistics (pp. 734-746). Amsterdam: Elsevier. http://grammar.ucsd.edu/labs/mayberrylab/papers/Mayberry_2ndLangLrng06.pdf https://doi.org/10.1016/B0-08-044854-2/05260-3 
Meulder, M. D. (2017). Promotion in Times of Endangerment: The Sign Language Act in Finland. Language Policy, 16, 189.

Modern Language Association (2017). Language Enrollment Database, 1958-2013. https://apps.mla.org/flsurvey_search https://doi.org/10.1007/s10993-016-9403-5

Mortensen, M. (2015). Sign of the Times: ASL Classes Soar in Popularity. HJ News. http://news.hjnews.com/allaccess/sign-of-the-times-asl-classes-soar-in-popularity/artic le_2cc5d5e4-e0af-11e4-b04a-6339deb4b6e6.html

Murphy, K. (2014). 7 Benefits of Online Learning. Schaumburg, IL: American Intercontinental University.

http://www.aiuniv.edu/blog/august-2014/7-benefits-of-online-learning

National Association of the Deaf (2018). Early Intervention Services. https://www.nad.org/resources/early-intervention-for-infants-and-toddlers/informatio $\underline{\text { n-for-parents/early-intervention-services/ }}$

National Post (2016). Federal Government Considers Making Sign Language Canada's Third Official Language.

http://nationalpost.com/news/canada/documents-show-federal-officials-looked-at-new -official-language-sign-language

Newell, W. J. (1994). A Job Analysis of Teaching American Sign Language. Doctoral Dissertation, Publication No. LD03041, 20, 03R.

Padden, C. (1980). The Deaf Community and the Culture of Deaf People. In C. Baker, \& R. Battison (Eds.), Sign Language and the Deaf Community (pp. 89-104). Silver Spring, MD: National Association of the Deaf.

Padden, C., \& Humphries, T. (1988). Deaf in America: Voices from Culture. Cambridge, MA: Harvard University Press.

Quinto-Pozos, D. (2011). Teaching American Sign Language to Hearing Adult Learners. Annual Review of Applied Linguistics, 31, 137-158. https://doi.org/10.1017/S0267190511000195

Registry of Interpreters for the Deaf (2014). Interpreter Education Program. https://myaccount.rid.org/Public/Search/Organization.aspx

Rochester Institute of Technology (n.d.). Innovative Learning Institute: Teaching and Learning Services. https://www.rit.edu/academicaffairs/tls/course-design/teaching-elements/goreactcom

Rosen, R. S. (2008). American Sign Language as a Foreign Language in U.S. High Schools: State of the Art. The Modern Language Journal, 92, 10-38. https://doi.org/10.1111/j.1540-4781.2008.00684.x

Rosen, R. (2010). American Sign Language Curricula: A Review. Sign Language Studies, 10, 348-381. https://doi.org/10.1353/sls.0.0050

Rosen, R. (2006). An Unintended Consequence of IDEA: American Sign Language, the Deaf Community, and Deaf Culture into Mainstream Education. Disability Studies Quarterly, 26, 35-35. http://dsq-sds.org/article/view/685/862

https://doi.org/10.18061/dsq.v26i2.685

Schermer, T. (2012). Sign Language Planning in the Netherlands between 1980 and 2010. Sign Language Studies, 12, 467-493. http://www.jstor.org/stable/26190876 https://doi.org/10.1353/sls.2012.0016

Schulz, R. (1996). Focus on Form in the Foreign Language Classroom: Students' and Teachers' Views on Error Correction and the Role of Grammar. Foreign Language, 29, 343-364. https://doi.org/10.1111/j.1944-9720.1996.tb01247.x 
Shroyer, E. H., \& Holmes, D. W. (1980). Sign Language Classes-The "in" Thing in Colleges and Universities. In Proceedings of the 1980 Registry of Interpreters for the Deaf Convention (pp. 75-80). Silver Springs, MD: RID Publication.

Siena School for Liberal Arts (2018a). About Siena School. http://www.sienaschool.com/About-Siena-School/

Siena School for Liberal Arts (2018b). Deaf Studies. http://www.sienaschool.com/Academics/Deaf-Studies/

Signature (2009). I-Sign Project: BSL Opportunities. http://www.signature.org.uk/news.php?article=51

Smith, C. (1988). Signing Naturally: Notes on the Development of the ASL Curriculum Project at Vista College. Sign Language Studies, 59, 171-182.

https://muse.jhu.edu/article/507625/summary https://doi.org/10.1353/sls.1988.0001

Smith, C., Lentz, E., \& Mikos, K. (2008). Signing Naturally Units 1-6 Teacher Curriculum Set. San Diego, CA: DawnSignPress.

Snodden, K. (2014). Hearing Parents as Plurilingual Learners of ASL. In D. McKee, R. S. Rosen, \& R. McKee (Eds.), Teaching and Learning Signed Languages (pp. 175-196). New York, NY: Palgrave MacMillan. https://doi.org/10.1057/9781137312495_9

Snoddon, K. (2016). Whose ASL Counts? Linguistic Prescriptivism and Challenges in the Context of Parent Sign Language Curriculum Development. International Journal of Bilingual Education and Bilingualism, 1-12. https://doi.org/10.1080/13670050.2016.1228599

Stockholm University (2018a). Department of Linguistics: Sign Language. https://www.ling.su.se/english/sign-language-section

Stockholm University (2018b). Department of Linguistics: Swedish as a Second Language for the Deaf.

https://www.ling.su.se/english/section-for-swedish-as-a-second-language-for-the-deaf

Stokoe, W. C. (1960). Sign Language Structure: An Outline of the Visual Communication System of the American Deaf. Studies in Linguistics, Occasional Papers, Vol. 8, Buffalo, NY: University of Buffalo.

Svartholm, K. (2010). Bilingual Education for Deaf Children in Sweden. International Journal of Bilingual Education and Bilingualism, 13, 159-174. https://doi.org/10.1080/13670050903474077

Tes, R. (2017). British Sign Language Will Count as "Foreign Language" for University Applicants. Tes Global Ltd.

https://www.tes.com/news/school-news/breaking-news/british-sign-language-will-cou nt-foreign-language-university

Universität Hamburg (2018). Institute of German Sign Language and Communication of the Deaf. https://www.idgs.uni-hamburg.de/en.html

University of Northern Colorado (2017). Teaching ASL. http://www.unco.edu/cebs/asl-interpreting/teaching-asl/

Utah State University (2009). Innovative ASL Program Could Have Lasting Impact. Utah State Today. http://www.usu.edu/today/index.cfm?id=33694

Valli, C., Lucas, C., Mulrooney, K. J., \& Villanueva, M. (2011). Linguistics of American Sign Language: An Introduction (5th ed.). Washington DC: Gallaudet University Press.

Vicdeaf (2011). About Sign Language: What Is Auslan (Australian Sign Language)? Victoria State Government. http://www.vicdeaf.com.au/content.asp?id=106\&cid=39 
Watzke, J. L. (2007). Foreign Language Pedagogical Knowledge: Toward a Developmental Theory of Beginning Teacher Practices. The Modern Language Journal, 91, 63-82. https://doi.org/10.1111/j.1540-4781.2007.00510.x

Wilcox, S. (2017). Universities That Accept ASL in Fulfillment of Foreign Language Requirements. http://www.unm.edu/ wilcox/UNM/univlist.html

Wilcox, S., \& Occhino, C. (2016). Historical Change in Signed Languages. Chicago, IL: Oxford Handbooks Online. https://doi.org/10.1093/oxfordhb/9780199935345.013.24

World Federation of the Deaf (2016a). News. https://wftdeaf.org/news/un-23-sept-as-international-day-of-sign-languages/

World Federation of the Deaf (2016b). Our Work. https://wfdeaf.org/our-work/

World Federation of the Deaf (2016c). Sign Language. https://wfdeaf.org/human-rights/crpd/sign-language/

Wright, P. (2010). The History of Special Education Law. http://www.wrightslaw.com/law/art/history.spec.ed.law.htm 